\title{
It is Time to put the Lid on Traumatic Brain Injuries in Scooter Crashes
}

\author{
${ }_{1}^{1}$ Gerd D Pust, ${ }^{2}$ Tara M Irani, ${ }^{3}$ Alejandro D Badilla, ${ }^{4}$ Casey J Allen, ${ }^{5}$ Chanyoung Lee, ${ }^{6}$ George D Garcia \\ ${ }^{7}$ Degino A Capellan, ${ }^{8}$ Antonio Marttos, ${ }^{9}$ Enrique Ginzburg, ${ }^{10}$ Nicholas Namias, ${ }^{11}$ Patricia M Byers
}

\begin{abstract}
Introduction: Rider education that stresses helmet usage has not reached the scooter population. The impression that scooters are a safe, low-speed means of transport often results in poor helmet compliance. However, severe head injuries are common in scooter crashes. We chose to evaluate whether helmet use in the scooter rider population is associated with a reduction of traumatic brain injury (TBI), skull, and c-spine injuries.
\end{abstract}

Materials and methods: A retrospective analysis of our Level I trauma center registry was performed identifying all patients treated for scooter crash-related injuries from 2003 to 2015. Helmet data were collected from Emergency Medical Services, police, and hospital records. Statistical analysis was performed using $\chi^{2}$, Mann-Whitney U-test, and z-test for proportions.

Results: Of 1,006 scooter crash patients, $13.3 \%$ of patients wore helmets at the time of their crash. Their mean age was $34.2 \pm 16$ years with an $80 \%$ male population. The Glasgow Coma Scale (GCS) in the unhelmeted group was nominally lower $(13.11 \pm 3.7)$ when compared with the helmeted group (13.92 \pm 2.8$)$. There were more TBIs $(61.6 \%)$ in unhelmeted patients vs helmeted patients $(36.6 \% ; p<0.0001)$. Of all helmeted patients, none presented with epidural hematomas, and helmeted patients suffered significantly fewer subdural hemorrhages, subarachnoid hemorrhages, and skull fractures when compared with unhelmeted patients $(p=0.008, p=0.005$, $p<0.0001$ respectively). Mortality was $4.0 \%$ in the unhelmeted group and $1.5 \%$ in the helmeted group $(p=0.215)$, but this difference did not reach statistical significance.

Conclusion: Helmet use significantly lowers the risk of TBI in scooter crashes. Additional multicenter trials are needed to study a possible survival benefit associated with helmet use. Educational and community outreach programs are needed urgently to improve helmet use compliance among scooter riders in order to reduce the $\mathrm{TBI}$ incidence.

\footnotetext{
${ }^{1}$ Assistant Professor, ${ }^{2,3,5}$ Student, ${ }^{4}$ Resident Physician, ${ }^{6,8}$ Associate Professor, ${ }^{7}$ Research Assistant, ${ }^{9-11}$ Professor

1-4,6-11 Division of Trauma and Surgical Critical Care, The DeWitt Daughtry Family Department of Surgery, Ryder Trauma Center/ Jackson Memorial Hospital Miller School of Medicine University of Miami, Miami, Florida, USA

${ }^{5}$ Center for Urban Transportation Research, University of Southern Florida, Miami, Florida, USA

Corresponding Author: Gerd D Pust, Assistant Professor Division of Trauma and Surgical Critical Care, The DeWitt Daughtry Family Department of Surgery, Ryder Trauma Center/ Jackson Memorial Hospital Miller School of Medicine University of Miami, Miami, Florida, USA, Phone: +13055851180 , e-mail: gpust@med.miami.edu
}

Keywords: Crash, Epidural, Helmet, Scooter, Skull fracture, Subarachnoid, Subdural, Traumatic brain injury.

How to cite this article: Pust GD, Irani TM, Badilla $A D$, Allen CJ, Lee C, Garcia GD, Capellan DA, Marttos A, Ginzburg E, Namias N, Byers PM. It is Time to put the Lid on Traumatic Brain Injuries in Scooter Crashes. Panam J Trauma Crit Care Emerg Surg 2018;7(1):72-76.

Source of support: Nil

Conflict of interest: None

\section{INTRODUCTION}

Scooters are a popular mode of transportation frequently used in Central and South America, Asia, the Caribbean, southern Europe, and the United States. Scooter riders are often under the impression that this means of low-speed motorized transportation is distinctly different and safer compared with motorcycles, resulting in low helmet compliance. Low helmet usage rates were also noticed in other studies. La Torre et $\mathrm{al}^{1}$ reported a very low helmet usage rate with only $5 \%$ of all scooter riders helmeted. However, after implementation of a universal helmet law mandating helmet use in motorcycle and scooter riders in Rome, Italy, in 2000, the helmet compliance rate in scooter riders increased to $90 \%$. Kyrychenko and McCartt ${ }^{2}$ demonstrated that the repeal of an existing helmet law in Florida in 1998 was associated with a decline in helmet usage from nearly 100 to $53 \%$ in motorcyclists by 2006 . Our latest trauma registry data show that over the last 10 years the helmet usage in scooter riders continued to see a dramatic decline to only $13.3 \%$. The World Health Organization reported in its 2004 World Report on Road Traffic Injury Prevention Summary $^{3}$ that powered two-wheelers (including motorcycles, mopeds, scooters) are associated with the highest rate of traffic deaths with 440 fatalities per million travel passenger hours. In comparison, fatality rates for other modes of travel are pedestrians 75 , cars 25 , bicycle 25 , bus 2 , and rail 2 deaths per million passenger-travel hours.

Incidence of TBIs in scooter crashes is reported in the literature with a range between 3.85 and $67.0 \%{ }^{1,4-6}$ The frequency of head injuries and TBIs varies based on geographic location and helmet use. White et al ${ }^{4}$ noticed that intracranial injuries were the third most common injuries after extremity fractures and internal organ injuries in a

Presented in the general competetion, annual Congress of Panamerican Trauma Society, Maceio, Brazil, November 2017 
It is Time to put the Lid on Traumatic Brain Injuries in Scooter Crashes

scooter crash patient population in Australia. Forman et $\mathrm{al}^{7}$ reported TBIs in $13.4 \%$ of powered two-wheeler (including motorcycle and scooters) crashes, with TBI being the second most common injury after extremity fractures in a European population with high helmet use compliance. La Torre et $\mathrm{al}^{1}$ reported a reduction of head injuries from 12.4 to $3.85 \%$ after introduction of a mandatory helmet law in Rome, Italy, which coincides with the aforementioned improvement in helmet compliance from 15 to $90 \%$.

Traumatic brain injuries are often associated with significant morbidity, mortality, long-term disability, and high health care costs. ${ }^{8,9}$

A thorough analysis of the literature reveals limited availability of detailed data in scooter-related TBIs. To the best of our knowledge, a detailed analysis of subtypes of TBIs in scooter crash victims and potential protective effects of helmet use is absent in the current literature.

The goal of this study is to evaluate whether helmet use in the scooter rider population is associated with a reduction of severe TBI, skull, and cervical spine injuries.

\section{MATERIALS AND METHODS}

A retrospective analysis of our urban Level I trauma center registry was performed identifying all adult trauma patients with scooter-related injuries between 2003 and 2015. Demographic, injury, and outcome data were collected and recorded using spreadsheet software (Microsoft Excel $^{\circledR}$ ). Helmet data were collected from emergency medical services, law enforcement, and hospital records. Computed tomography scan reports were reviewed to collect exact information on presence and type of TBIs. Additional data points on presence of skull fractures and cervical spine injuries were recorded. Medical records were queried for documentation of symptoms consistent with concussion. Statistical analysis was performed using $\chi^{2}$ for independent normally
Table 1: Demographic and TBI data in scooter crash patients with and without helmet use

\begin{tabular}{llll}
\hline & Helmet & No helmet & $p$-value \\
\hline Total patients & $134(13.3 \%)$ & $872(86.7 \%)$ & - \\
Male & $106(79.1 \%)$ & $701(80.4 \%)$ & 0.364 \\
Mean age & $35.98 \pm 15.8$ & $33.96 \pm 16.2$ & 0.179 \\
GCS (arrival) & $13.92 \pm 2.8$ & $13.11 \pm 3.7$ & 0.007 \\
Total TBI & $49(36.6 \%)$ & $537(61.6 \%)$ & $<0.0001$ \\
Epidural hematoma & $0(0 \%)$ & $52(6.0 \%)$ & - \\
Subdural hematoma & $10(7.5 \%)$ & $132(15.1 \%)$ & 0.008 \\
Subarachnoid & $18(13.4 \%)$ & $202(23.2 \%)$ & 0.005 \\
hemorrhage & & & \\
Diffuse axonal injury & $5(3.7 \%)$ & $47(5.4 \%)$ & 0.21 \\
Concussion & $16(11.9 \%)$ & $104(11.9 \%)$ & 0.498 \\
Skull fracture & $11(8.2 \%)$ & $226(25.9 \%)$ & $<0.0001$ \\
C-spine injuries & $5(3.7 \%)$ & $50(5.7 \%)$ & 0.171 \\
Mortality & $2(1.5 \%)$ & $35(4.0 \%)$ & 0.215 \\
\hline
\end{tabular}

distributed data; Mann-Whitney U-test for two independent sample group comparison, ordinal data; and z-test for proportions $(\mathrm{p}<0.05)$ for categorical data points. IBM Statistical Package for the Social Sciences software was used to complete the statistical analysis. Institutional review board approval was obtained for this study.

\section{RESULTS}

A retrospective analysis of our Level I trauma center registry revealed 1006 scooter crash victims between 2003 and 2015 . About $80 \%$ of the patients were male. Their mean age was $34.2 \pm 16$ years.

Total $134(13.3 \%)$ patients were wearing a helmet at the time of the accident (Table 1). The incidence of TBI was $61.6 \%$ significantly higher in the unhelmeted group compared with $36.6 \%$ in the helmeted group $(\mathrm{p}<0.0001)$ (Graph 1). Skull fractures were more common in the unhelmeted group (25.9 vs 8.2\%, p<0.001). About $6 \%$ of patients in the unhelmeted group had epidural hematomas; no patients in the helmeted group developed an

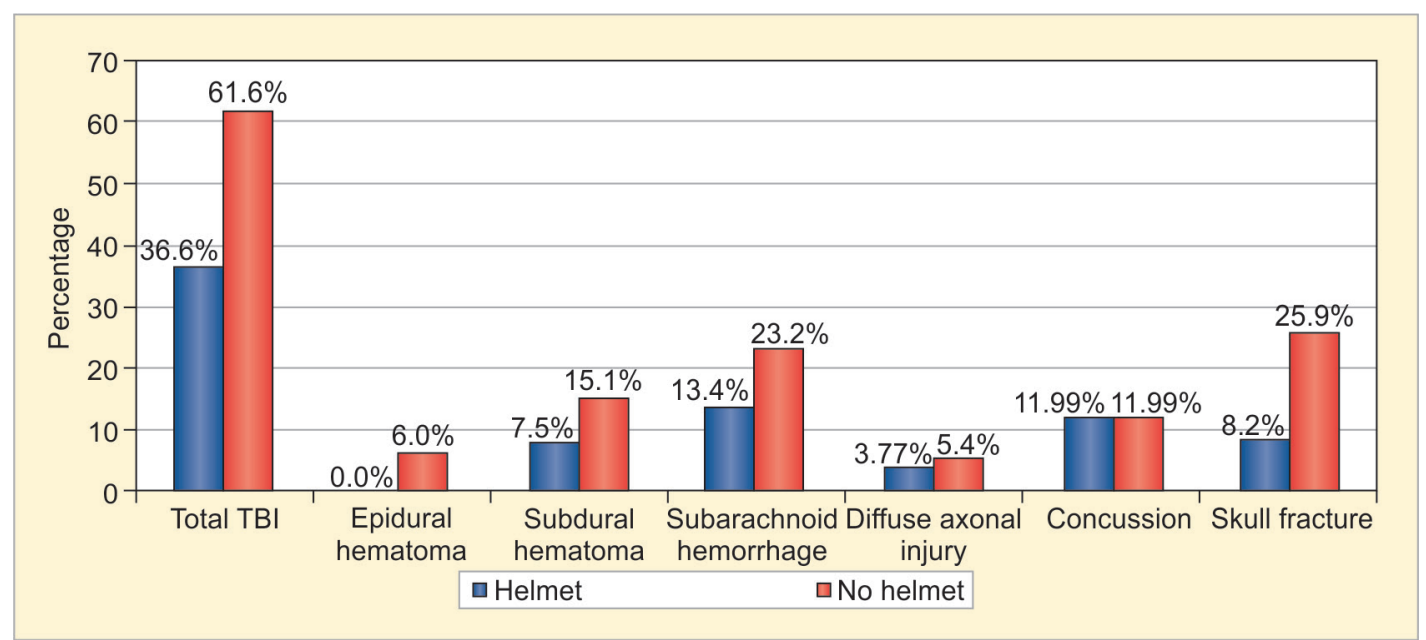

Graph 1: The TBI distribution in scooter crash patients' helmet vs no helmet 
epidural hematoma. The unhelmeted group had higher rates of subarachnoid hemorrhage (23.2 vs 13.4\%, p = 0.005 ) and subdural hemorrhage (15.1 vs 7.5\%, $\mathrm{p}=0.008$ ). Diffuse axonal injury rates were similar between the helmeted and unhelmeted group ( 3.7 vs $5.4 \%, \mathrm{p}=0.21$ ).

Interestingly, the rate of concussion was similar in both groups (11.9 vs $11.9 \%, \mathrm{p}=0.498$ ). Cervical spine injuries were not significantly different in both groups, with $3.7 \%$ in the helmeted group and $5.7 \%$ in unhelmeted group $(\mathrm{p}=0.171)$.

The mortality in the unhelmeted group was 4.0 and $1.5 \%$ in the helmeted group $(\mathrm{p}=0.215)$.

\section{DISCUSSION}

Studies ${ }^{1,4-8,10-13}$ published in the literature as well as our recent urban Level I trauma center data demonstrate that the incidence of severe TBIs is very high. Scooters are often used in densely populated urban areas for short commutes on city roads rather than highways. Visibility of scooter riders compared with other motor vehicles is limited, and, as a result, scooter drivers are often overlooked. Kosola et al ${ }^{5}$ found that $52 \%$ of scooter accidents were a result of a collision with another vehicle compared with $33 \%$ resulting from falls. Scooters are popular in young age groups, and injured patients are predominantly male. Risk factors associated with more severe injuries are accidents at night, average driving speed of $25 \mathrm{mph}$, and being under the influence of alcohol or drugs. ${ }^{10}$ Similar to pedestrians hit by a motor vehicle, scooter drivers have minimal physical protection during an accident. As described in the 2004 World Health Organization World Report ${ }^{3}$ on Road Traffic Injury Prevention Summary, the fatality rates of powered two-wheelers (including motorcycles, mopeds, scooters) are-with 440 fatalities per million travel passenger hours-staggeringly high; 17-fold higher than cars (25 fatalities per million travel passenger hours) and 220-fold higher than public transport with bus or train ( 2 fatalities per million travel passenger hours). Based on these data, a serious discussion and review should be undertaken to improve powered two-wheeler safety profile. Increased focus needs to be on scooter rider safety education, accident prevention, and safety gear.

Multiple studies ${ }^{1,2,6,11,12}$ as well as our own data clearly show that helmet use in scooter drivers is not popular. However, La Torre et $\mathrm{l}^{1}$ data clearly show that introduction of laws mandating helmet use for scooter riders and strict enforcement can result in a dramatic increase of helmet use from 15 to $90 \%$. In concurrence with this pattern, Florida observed a dramatic decline of helmet use by motorcycle riders from nearly 100 to $53 \%$ after repeal of mandatory helmet laws in 1998. Our data show that the helmet use in scooter crash victims presenting to our trauma center was even much lower with only $13.3 \%$. Only one out of seven scooter crash victims was wearing a protective helmet at the time of the accident. Our data show that, in scooter crash patients presenting to our trauma center, the likelihood of sustaining a TBI was almost twice as high (61.6 vs 36.6\%) without a helmet. More importantly, the number of patients with severe TBIs including epidural hematomas, subdural and subarachnoid hemorrhage, and skull fractures were all significantly reduced in patients wearing a helmet during the accident. The number of non-anatomic TBIs (concussions) was similar in both groups. One explanation could be that the presence of a helmet reduced a potentially more severe anatomic TBI to a concussive type of TBI.

The repeal of Florida helmet laws for motorcyclists resulted in an estimated increase of $48.6 \%$ motorcycle occupant deaths the year after the repeal of mandatory helmet laws. ${ }^{14}$ Our data suggest a potential trend toward a reduction in mortality in scooter riders wearing a helmet at the time of the accident (1.5 vs 4.0\%), but this current study might be underpowered in order to detect a potentially significant difference.

This study has several limitations requiring additional discussion. The described data represent a cohort of scooter crash patients treated at our Level I trauma center. This dataset does not represent all scooter crash patients in our community, since trauma patients are treated at several trauma centers throughout our urban area. Furthermore, a selection bias may be present, since patients transported to a trauma center may be more severely injured compared with patients with minor injuries seeking care at nontrauma center hospitals. This study does not include on-scene deaths transported outside our trauma center. Additional research work reviewing medical examiner datasets is required to review the impact of head injuries in on-scene scooter fatalities.

In conclusion, scooter crash patients presenting to our urban Level I trauma center wearing helmets at the time of the accident had a significant reduction of severe TBIs. Helmet use for scooter riders without a doubt is highly recommended, and mandatory helmet laws are proven to be effective in elevating compliance rates to acceptable levels. Additional multicenter studies are needed to better understand the impact of helmets and other protective devices in scooter accident patients. Long-term outcome of TBIs, associated morbidity and disabilities, as well as related health care cost in this patient population require further research. Trauma center community outreach programs focusing on scooter rider safety education and helmet use may be beneficial in raising awareness among scooter riders. 


\section{REFERENCES}

1. La Torre G, Van Beeck E, Bertazzoni G, Ricciardi W. Head injury resulting from scooter accidents in Rome: differences before and after implementing a universal helmet law. Eur J Public Health 2007 Dec;17(6):607-611.

2. Kyrychenko SY, McCartt AT. Florida's weakened motorcycle helmet law: effects on death rates in motorcycle crashes. Traffic Inj Prev 2006 Mar;7(1):55-60.

3. Organization W.W.H. World Report on Road Traffic Injury Prevention: Summary; 2004.

4. White D, Lang J, Russell G, Tetsworth K, Harvey K, Bellamy N. A comparison of injuries to moped/scooter and motorcycle riders in Queensland, Australia. Injury 2013;44(6):855-862.

5. Kosola S, Salminen P, Laine T. Heading for a fall-moped and scooter accidents from 2002 to 2007. Scand J Surg 2009; 98(3):175-179.

6. Ganti L, Bodhit AN, Daneshvar Y, Patel PS, Pulvino C, Hatchitt K, Hoelle RM, Peters KR, Kuchibhotla S, Lottenberg $\mathrm{L}$, et al. Impact of helmet use in traumatic brain injuries associated with recreational vehicles. Adv Prev Med, 2013;2013:450195.

7. Forman JL, Lopez-Valdes FJ, Pollack K, Heredero-Ordoyo R, Molinero A, Mansilla A, Fildes B, Segui-Gomez M. Injuries among powered two-wheeler usersin eightEuropean countries: a descriptive analysis of hospital discharge data. Accid Anal Prev 2012 Nov;49:229-236.

8. Majdan M, Mauritz W, Wilbacher I, Janciak I, Brazinova A, Rusnak M, Leitgeb J. Traumatic brain injuries caused by traffic accidents in five European countries: outcome and public health consequences. Eur J Public Health 2013 Aug;23(4): 682-687.

9. McIntyre A, Mehta S, Janzen S, Aubut J, Teasell RW. A metaanalysis of functional outcome among older adults with traumatic brain injury. NeuroRehabilitation 2013;32(2):409-414.

10. Miggins M, Lottenberg L, Liu H, Moldawer L, Efron P, Ang D. Mopeds and scooters: crash outcomes in a high traffic state. J Trauma 2011 Jul;71(1):217-222.

11. Mueller TS, Scooter crashes at university: intervention tactics for modified behavior and helmet use. Traffic Inj Prev 2013;14(4):335-339.

12. Siddiqui SM, Sagar S, Misra MC, Gupta A, Crandall M, Swaroop M. Patterns of injury among motorized twowheeler pillion riders in New Delhi, India. J Surg Res 2016 Sep;205(1):142-146.

13. Sood S. Survey of factors influencing injury among riders involved in motorized two-wheeler accidents in India: a prospective study of 302 cases. J Trauma 1988 Apr;28(4):530-534.

14. Muller A. Florida's motorcycle helmet law repeal and fatality rates. Am J Public Health 2004 Apr;94(4):556-558. 


\section{It's Time to Put the Lid on Traumatic Brain Injuries in Scooter Crashes}

Traumatic brain injury is a major problem worldwide. It represents at least half of all trauma-related deaths and impacts on high costs for health systems, for the support of treatment and rehabilitation of patients, ${ }^{1,2}$ with an estimated 10 million people to be affected by 2020 and road accidents becoming the third cause of global burden of disease and disability. ${ }^{3}$ In the United States, the costs are estimated in billions of dollars per year, since in 1997, annual costs were from USD222,600 to USD49,688 per patient depending on the level of disability. ${ }^{4}$

Modern trauma response equipment, new diagnostic aids, neurosurgical centers, and intensive care treatment have contributed to the reduction of mortality rates for patients with traumatic brain injury, where the series available in the literature report mortality from 35 to $42 \%$, especially in individuals aged between 15 and 25 years. The use of recreational vehicles has increased in popularity as well as the increase in injuries from falls. One of the high-risk practices is the use of scooters; these vehicles are often used by children and young people. ${ }^{5}$

The prevention of neurotrauma is one of the most powerful tools to face the devastating effects of injuries. It has been shown that the lack of use of helmets is associated with increases of intracranial injuries. It is well known that the use of helmets is associated with the reduction of morbidity and mortality in traumatic brain injury. ${ }^{6}$ On the contrary, some have argued that the use of helmets reduces the freedom of people. The article provides relevant information to reaffirm the need of an educational plan for prevention strategies and safe practices, e.g., helmets' use to drive scooters.

\section{REFERENCES}

1. Moscote-Salazar LR, Rubiano AM, Alvis-Miranda HR, Calderon-Miranda W, Alcala-Cerra G, Blancas Rivera MA, Agrawal A. Severe cranioencephalic trauma: prehospital care, surgical management and multimodal monitoring. Bull Emerg Trauma 2016 Jan;4(1):8-23.

2. Hyder AA, Wunderlich CA, Puvanachandra P, Gururaj G, Kobusingye OC. The impact of traumatic brain injuries: a global perspective. NeuroRehabilitation 2007;22(5):341-353.

3. Thornhill S, Teasdale GM, Murray GD, McEwen J, Roy CW, Penny KI. Disability in young people and adults one year after head injury: prospective cohort study. BMJ 2000 Jun;320(7250):1631-1635.

4. Ashley MJ, Schultz JD, Bryan VL, Krych DK, Hays DR. Justification of postacute traumatic brain injury rehabilitation using net present value techniques: a case study. J Rehabil Outcomes Meas 1997;1(5):33-41.

5. Hoz S, Moscote-Salazar LR. Prevention of neurotrauma: an evolving matter. J Neurosci Rural Pract 2017 Aug;8(Suppl S1):141-143.

6. Michael PD, Davenport DL, Draus JM Jr. Bicycle helmets save more than heads: experience from a pediatric level I trauma hospital. Am Surg 2017 Sep 1;83(9):1007-1011.

Luis Rafael Moscote-Salazar Cartagena Neurotrauma Research Group-CIB University of Cartagena, Cartagena, Colombia 